\title{
Habitat selection and breeding success in a forest-nesting Alcid, the marbled murrelet, in two landscapes with different degrees of forest fragmentation
}

\author{
Yuri Zharikov • David B. Lank · Falk Huettmann · Russell W. Bradley \\ Nadine Parker - Peggy P.-W. Yen · Laura A. Mcfarlane-Tranquilla • \\ Fred Cooke
}

Published online: 30 March 2007

(C) Springer Science+Business Media B.V. 2007

\section{Erratum to: Landscape Ecol 21: 107-120 \\ DOI 10.1007/s10980-005-1438-5}

Corrections:

Fig. 2 (page 113) and Table 2 (page 115) "Elevation" 2 " should read "ln(Elevation $\left.{ }^{2}\right) "$.

The online version of the original article can be found at http://dx.doi.org/10.1007/s10980-005-1438-5

Y. Zharikov · D. B. Lank · F. Huettmann .

R. W. Bradley · N. Parker · P. P.-W.Yen ·

L. A. Mcfarlane-Tranquilla - F. Cooke

Centre for Wildlife Ecology, Department of

Biological Sciences, Simon Fraser University,

Burnaby, BC, CanadaV5A 1S6

Y. Zharikov $(\bowtie)$

School of Integrative Biology, University of Queensland, Brisbane, QLD 4072, Australia e-mail: yzharikov@zen.uq.edu.au

\section{F. Huettmann}

Department of Biology and Wildlife, Institute of Arctic Biology, University of Alaska Fairbanks,

Fairbanks, AK 99775, USA

R. W. Bradley · N. Parker · P. P.-W.Yen PRBO Conservation Science, 4990 Shoreline Highway, Stinson Beach, CA 94970, USA

F. Cooke

Larkin's Cottage, 6 Lynn Road, Castle Rising,

Norfolk PE31 6AB, UK

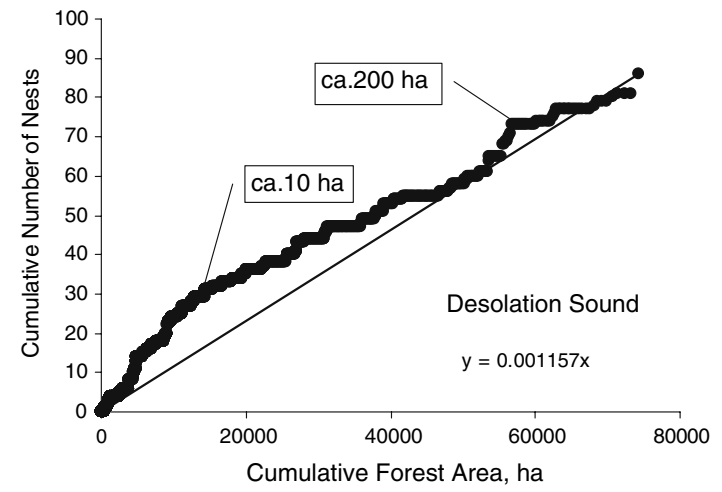

Fig. 2 Top 